\title{
Representações sociais de professores sobre o trabalho que fazem na escola
}

\author{
Ivany Pinto Nascimento* \\ Universidade Federal do Pará
}

\begin{abstract}
Resumo
Este estudo investigou as representações sociais de professores do ensino fundamental sobre o trabalho que realizam e os desafios dessa prática. O estudo se caracterizou como descritivo, empírico, qualitativo e interpretativo com base na Teoria das Rs. Foi realizado com 50 docentes do sexo feminino. $\mathrm{O}$ instrumento de coleta de dados foi a entrevista com a abordagem nas seguintes temáticas: a representação que o professor faz sobre seu trabalho neste contexto histórico-social; e os desafios que encontram para realizá-lo. Os resultados indicam que as representações sociais, ancoram seus sentidos na insatisfação com a profissão e com as condições de trabalho.
\end{abstract}

Palavras-Chave: representações sociais, professores, profissão.

\begin{abstract}
This study investigated the social representations of elementary school teachers about the work they do and the challenges of this practice. The study characterized as descriptive, qualitative and interpretive empirical, based on Rs theory. Was conducted with 50 female teachers. The data collection instrument was the interview with the approach on the following themes: the representation that the teacher makes about his work in this historical-social context; and the challenges they encounter it. The results indicate that the social representations, anchor your senses on dissatisfaction with the profession and working conditions.
\end{abstract}

Key words: social representations, teachers profession.

Este artigo objetiva compartilhar os resultados de pesquisa sobre as representações sociais de professores de séries iniciais sobre o trabalho docente e suas perspectivas. Faremos uma introdução ao tema investigado seguida da apresentação de seus resultados.

Nas últimas décadas questionamentos sobre o trabalho do professor se intensificaram em várias perspectivas. Fosse em função do alunado e de seus responsáveis e/ou pais, fosse da escola, ou da sociedade de maneira geral. Tais indagações se vinculam a inúmeros fatores, sobretudo aqueles que se relacionam a qualidade do ensino na escola.

A discussão sobre a nova cultura para ensinaraprender-trabalhar, com a qual o professor se defronta, é fundamental na atualidade, na medida em que as pressões sobre a reorganização do trabalho do professor se fazem presentes, em virtude de um conhecimento que não é duradouro (BAUMAN, 2009). Isso implica a flexibilidade para aprender o novo, inovar, criar articulações com a realidade e outras áreas de conhecimento, utilizar estratégias que motivem seus alunos etc.

Neste sentido, os níveis de complexidade da profissão professor acompanham dimensões que vão além de novas aprendizagens e metodologias atualizadas. A complexidade incide na condição existencial do professor que congrega vários sentidos e saberes, os quais convergem para aspectos objetivos e subjetivos de sua identidade de professor. Daí que o seu ser e o seu fazer incidem em mudanças individuais e coletivas.

Os valores que dão corpo, tanto à profissão quanto às representações que se formam em torno desse sujeito professor, não somente consolidam a formação acadêmica como também edificam subjetividades que, ao longo desta formação, transformam traços de personalidade e agregam princípios éticos e morais que vão constituir formas de pensar, de sentir e de agir na condição de professor.

As pesquisas sobre formação de professores no Brasil, segundo as pesquisadoras Gatti, Barreto e André (2011) aumentaram significativamente nos últimos anos. Os estudos no campo da educação feito por André (2009) citado por estas autoras constatam que em 1990 as produções de dissertações e teses dos programas de pósgraduação em educação, cujo foco era a formação de professores, chegavam em 7\%. Em 2000 esse percentual foi para $22 \%$. Além de aumentarem o número de produções sobre esta temática, os objetos de estudo se diversificaram. Se, em 1990, o objetivo destes estudos era a formação inicial (75\%), no ano 2000 o objetivo centrou-se no professor, seus saberes, suas práticas, seus pensamentos e as suas representações alcançaram 53\%.

Os estudos que destinam suas investigações aos professores são importantes na medida em que desvelam caminhos para compreender e pensar nos inúmeros aspectos, como a formação, a profissão, as atividades vinculadas ao processo ensino-aprendizagem, que concorrem para a sua qualidade ou a comprometem.

Os estudos sobre a formação de professores assinalam que a Teoria das Representações Sociais, criada por Moscovici (2003) em muito contribuem para se apreender as representações de professores das series iniciais, sobre a prática, sobre a profissão etc. Estes conhecimentos propiciam intervenções e reorganizações sobre o curso além da compreensão sobre o tipo de

*Docente, Pesquisadora . Pesquisa Financiada pelo Conselho Nacional de Desenvolvimento Científico e Tecnológico - "National Counsel of Technological and Scientific Development". E-mail: ivany.pinto@gmail.com

Selección y peer-review bajo responsabilidad del Grupo de Investigación G000422-GIPDAE, Universidade da Coruña, España. 
profissional que o curso qualifica para atuar na sociedade.

\section{Trajetória metodológica}

A pesquisa objetivou identificar as representações sociais de professores das séries iniciais sobre o trabalho do professor e suas perspectivas.

\section{A seleção da amostra}

A pesquisa foi realizada com professoras das séries iniciais de escola públicas situadas em Belém.

\section{Instrumentos de pesquisa}

Utilizamos o questionário que foi aplicado a 50 professoras das series iniciais. Após, realizamos entrevistas de aprofundamento com 30 sujeitos voluntários que preencheram o referido questionário.

Constatamos a predominância do sexo feminino no magistério. Em 1827, a Lei de 15 de Outubro implantou as primeiras escolas primárias para o sexo feminino em todo o Império. Como naquela época, no Brasil e também na Europa, as aulas eram ministradas em turmas separadas por sexo. Deste modo, as primeiras vagas foram criadas para professoras para lecionarem nas turmas femininas, Demartini (1991:32). Ela explica que "a Escola Normal, então, passou a representar uma das poucas oportunidades, se não a única, das mulheres prosseguirem seus estudos além do primário". De acordo com a autora, desde a criação das primeiras Escolas Normais no Brasil, ficou determinado em lei que o magistério público poderia ser exercido por mulheres.

A teoria das representações sociais, criada por Moscovici (1978), a partir do redimensionamento do conceito de representações coletivas de Durkheim (1898) funcionou, neste estudo, como uma referência fundamental para compreender como são produzidas as imagens e os sentidos consensuais sobre o trabalho docente de professores das séries iniciais e suas perspectivas. Estas imagens funcionam como objetivações, e os sentidos como ancoragens que, segundo Moscovici, são dois processos pelos quais as representações se organizam e se consolidam.

O problema gerador deste estudo: Quais são as representações sociais de professores das series iniciais sobre o trabalho do professor e suas perspectivas na contemporaneidade?

Com base em Moscovici, entendemos que as representações sociais são conhecimentos socialmente construídos sobre a realidade e partilhados nas interações entre os grupos. A lógica que institui estes conhecimentos ultrapassa a razão formal, aquela que se liga diretamente ao fato em si. Assim, o campo psicossocial, que organiza as construções mentais, só pode ser compreendido à luz do contexto que o engendra, e das funções que ocupa nas interações sociais do cotidiano (JODELET, 1989).

Para a análise qualitativa das informações, utilizamos a análise de conteúdo que se caracteriza como um conjunto de técnicas de análise das comunicações (BARDIN, 1997, p. 31). O discurso desses professores entrevistados foram agrupados pelas unidades de significados. Essas unidades formaram redes temáticas analíticas que deram base para identificar as objetivações e ancoragens que se inscrevem no processo de composição das representações sociais de professores das series iniciais sobre o trabalho do professor e suas perspectivas na contemporaneidade (NASCIMENTO, 2009).

\section{Caracterização da população}

Os professores são das primeiras séries do ensino fundamental do turno matutino se encontram na faixa etária de 25 a 45 anos, distribuídos entre o sexo feminino e o masculino, este em menor número. Observamos que é um dado comum existir, maior número de professoras conforme mencionado anteriormente - no caso presente são 50 professoras.

\section{O que dizem os professores?}

\section{a) Formação inicial em pedagogia}

Os entrevistados revelam que nutrem muitas dúvidas, pois sentem que o Curso de Pedagogia que fizeram foi muito teórico e a prática bem menor, Contudo é consenso que o curso foi bom e prepara para ser professor e aprovação em concurso da área. A fala de uma das professoras representa esse pensamento:

O curso que nos fazemos é muito teórico e falta a prática e isso nos deixa um pouco em dúvida quanto o futuro. No geral é um curso bom, dá condições de passar em concurso da área e ser professor.

As pesquisadoras Gatti, Barreto e André (2011, p. 114) ao estudarem as ementas das disciplinas dos Cursos de Pedagogia evidenciam que existe grande um grande foco na oferta de conteúdos teóricos. Segundo elas, isso é realmente muito importante para o trabalho consciente do(a) professor(a), mas não suficiente para o desempenho de suas atividades de ensino. Possivelmente o Curso de Formação de Professores ainda não venceu o desafio de articular adequadamente a teoria com a prática na medida em que essa queixa é bem antiga.

\section{b) A característica importante para se tornar professor}

Quando falam sobre o que é importante para se tornar professor nos dias de hoje, as crenças desses professores se encaminham para um rol de características que o professor deve possuir. Abaixo, destacamos aquelas que representam o pensamento coletivo das entrevistadas:

A vocação, o amor à profissão, a formação permanente, o gostar de crianças e saber lidar com elas, saber ensinar, ensinar o aluno a ser cidadão e prepará-lo para um futuro melhor e para o mercado de trabalho $e$ a ter muita garra.

Este conjunto de características que o professor deve possuir, segundo os entrevistados, faz parte da identidade deste profissional assim como são construídas em função dos padrões sócio culturais. 


\section{c) Representação do professor}

A função do professor se assemelha à do psicólogo quanto à compreensão do que ele deve ter sobre o aluno. Deve ser constante a ética, a descrição, a fé e a esperança de que o aluno aprende e se prepara para a vida. Segundo as professoras entrevistadas, estas são as características que o professor deve possuir e que se assemelham à de um padre. Enquanto semelhança com um padeiro é consenso para esses entrevistados que o professor trabalha muito, para moldar o aluno. Segundo essas professoras: alguns ele consegue outros não. Por analogia, o aluno para essas professoras é como se fosse uma massa. Os ensinamentos do professor, a sua compreensão e a sua fé são os ingredientes fundamentais para que o aluno.

Estes professores, ao avaliarem como representam o trabalho do professor neste cenário de desafios e superações, são unânimes em afirmar que o lugar do professor é de grande valor para a sociedade. Muito embora exista uma contradição quanto a este reconhecimento, uma vez que não somente a infraestrutura na qual o professor realiza o seu trabalho é inadequada, como também a remuneração que o professor recebe, evidencia muito mais a desvalorização do que a valorização por aquilo que fazem e representam. Associado à falta de reconhecimento e desvalorização pelo trabalho que o professor realiza, comparece também o desprestígio por esta profissão. A frustração dessas professoras transita entre o idealizado e o vivido pela profissão que produz em cada uma deles a decepção com o que escolheram para trabalhar.

Estas condições e contradições de acordo com Gatti (2011) devem ser alvo de estudos para se aprofundar a compreensão sobre as dimensões social, afetiva e cultural, dentre outras, que envolvem o trabalho do professor.

As falas das duas alunas abaixo traduzem estes pensamentos:

O papel do professor é importante para a sociedade. $\grave{E}$ com ele que tudo começa. A criança inicia o seu caminho no aprendizado e vai se desenvolvendo. $O$ ensino é a base para a formação das pessoas que fazem parte da sociedade.

Apesar de o professor ser uma figura importante para a sociedade, eles são muito desvalorizados e isto faz com que os alunos desconheçam o nosso valor na vida deles.

\section{d) Desafio de educar e descobrir novos métodos de ensino motivadores:}

O trabalho do professor para essas informantes é desafiador sempre. O professor deve descobrir novos métodos de ensino que motivem os alunos na medida em que os que são conhecidos e utilizados já não conseguem despertar o interesse deles pela aprendizagem. Dai que a maioria das entrevistadas possui o consenso de que a qualificação do professor é imprescindível para a aprendizagem do aluno. Uma das alunas de pedagogia nos diz:
O que o professor faz é um desafio. Ele tem sempre que buscar novos métodos de ensino que despertem no aluno a motivação para aprender. As metodologias que já estão em uso não conseguem despertar o aluno para aprendizagem. A qualificação do professor é fundamental.

\section{e) Qualificação para trabalhar com novas situações presentes na sala de aula}

Segundo as entrevistadas, o professor deve prepararse para trabalhar com as novas situações que comparecem na sala de aula e na sociedade. Por exemplo: alunos com necessidades especiais, alunos que só possuem pai, e outros que só têm mãe, as diferenças, o preconceito, a sexualidade, bullying, etc. As falas de duas professoras representam o consenso entre elas:

$O$ professor tem que preparar o aluno para a vida $e$ aceitar a realidade. Uns tem só o pai, outros só tem a mãe ou a avó. Tem aluno que é surdo, outro é cego, aquele aluno com síndrome. Como vamos lidar com eles?

Ah! Tem aluno que é afeminado, tem aluna que é igual a um menino, tem aluno negro e outras coisas mais. Tem menino que apelida, ameaça os outros. Olha não é fácil, temos que ter sempre uma qualificação. A sociedade mudou

\section{f) A motivação/desmotivação pelo trabalho}

As professoras ao nos falarem da motivação que sentem pelo trabalho que fazem afirmam que ela vem do aprendizado sobre o desenvolvimento da criança. Além de gostarem de criança, também gostam de ensinar-lhes. Com base nas suas vivências elas dizem que a família dos alunos não se constitui em fonte de motivação no trabalho que fazem. Elas destacam, que os pais, em sua maioria, são distantes e pouco ajudam seus filhos. Às vezes prejudicam e causam mais problemas do que os próprios alunos. Eles, hoje em dia, se responsabilizam menos pelos filhos. Elas consideram que os pais não sabem educar seus filhos por que os deixam fazer o que querem.

A fala das professoras exemplificam as ideias que eles partilham sobre a família:

(...) na maioria das vezes a mãe e o pai acham que a escola é que deve educar e eles não assumem a educação do filho. Eles fazem o que querem e não acontece nada.

(...) Se os professores fossem esperar pela família deles eles não seriam nada. Tá difícil hoje os pais saberem educar.

A dificuldade de educar na contemporaneidade decorre do rompimento com as concepções tradicionais que orientavam a educação e as praticas educativas, fossem elas familiares ou escolares. As regras de condutas sofreram transformações no tempo, o que 
torna necessário a problematização sobre a finalidade da educação escolar e da prática educativa para a formação do sujeito frente ao processo de mudança social permanente, nos dias atuais. Isto representa uma lacuna para tanto para a família quanto para a escola.

A afirmação de que a educação é um processo natural - e que, portanto, as duas instâncias família e escola saberiam, de antemão o que ela significa - não é verdadeira. A educação é construída em um complexo relacional que carrega um significante da ordem da polissemia.

\section{g) A saúde/adoecimento do professor}

Constatamos que a saúde de dez das professoras se encontrava comprometida, o que se tornou fonte de desmotivação em suas atividades na escola, com seus alunos. Sete das professoras entrevistadas se queixava de cansaço e as outras três de inflamação constante de suas cordas vocais, dores nas costas e varizes.

O frequente adoecimento do professor está vinculado à desestabilização de sua subjetividade. Ele se reflete na relação do professor com os aspectos que configuram o seu trabalho e a sua identidade profissional. Esta identidade é uma das dimensões que compõem a identidade do sujeito, isto é, a consciência que o professor, possui dele mesmo. Existem, é claro, outras dimensões na composição da identidade do sujeito que refletem a identidade profissional e vice versa (NASCIMENTO, 1998).

\section{h) A distribuição do tempo/ trabalho}

Um ponto de destaque na fala das entrevistadas é a disponibilidade de tempo do professor para o planejamento de várias atividades escolares ao levar em consideração que grande parte do tempo dessas professoras é dedicado à sala de aula. Segundo elas, sobra pouco tempo para o planejamento de atividades, correção de trabalhos e das provas, leitura, pesquisa e reuniões com a coordenação ou pais dos alunos, sem contar que as atividades da vida privada, tornam-se bastante restritas. Nos finais de semanas, de acordo com suas informações, elas se dividem entre o planejamento escolar e as atividades de casa. Vejamos a transcrição abaixo da fala de uma das professoras sobre o assunto mencionado:

A nossa vida é de dedicação com a escola, com os alunos o tempo que sobra para outras coisas da nossa vida, ainda dividimos com os afazeres da escola como: preenchimento do diário de classe, correção de provas de trabalhos, planejamento semanal, avaliação... A escola cobra, e nós fazemos pois gostamos de ter tudo organizado.

A essas atividades mencionadas pelas entrevistadas somam-se, ainda, o tempo gasto para deslocamentos entre residências e escolas em que atuam e vice versa. Conforme a fala de uma das professoras informantes:

O que sobra de tempo segundo estes entrevistados (...) é muito pouco tempo para o lazer, cultura e vida pessoal.
A sugestão de um ritmo de trabalho que contemplasse as necessidades do professor para além da sala de aula constitui-se em uma das demandas comuns dessas professoras que, certamente, contribuiria com a vida e com a boa saúde como também com o seu trabalho.

Hargreaves (1999) analisa a intensificação do tempo de trabalho do professor e afirma que ele reduz tanto o tempo disponível dedicado para uma atividade de sua vida privada quanto o tempo dedicado a sua atualização. Isto acarreta uma sobrecarga que reduz a qualidade de seu trabalho e do seu profissionalismo.

\section{i) Avaliação sobre o trabalho que o professor realiza}

Mesmo correndo contra o tempo, expressão utilizada pelas professoras, elas, avaliam suas atuações como satisfatórias diante da ginástica que, na visão delas, fazem todos os dias. Conforme a fala de duas delas:

A ginástica que fazemos é grande para dar conta da aprendizagem dos alunos. A gente sabe que a cobrança vai para o professor

A aprovação do aluno no final do ano vem pra cima do professor. $O$ pai não quer saber se ele mesmo não ajudou. Ele pressiona a escola e o professor.

O ensino, de acordo com o pensamento dessas professoras ainda se encontra centrado no conteúdo. A escola permanece a mesma, sem acompanhar as mudanças da sociedade e as necessidades educacionais e de escolarização dos alunos que não são as mesmas, posto que vivem realidades bem diferentes do contexto histórico social de 10 anos atrás.

A imagem do trabalho do professor se materializa para essas professoras alvo do estudo entre a descrença pela desvalorização que atribuem ao trabalho deste profissional por um lado e, por outro, a quase certeza na possibilidade de se inserir no mercado de trabalho, uma vez que o papel do docente é importante para a educação do aluno e que, portanto, ele deve persistir para mudar este cenário.

Estas demandas com as quais o professor se defronta fazem com que as pressões sobre a reorganização do trabalho do professor sejam permanentes, em virtude de um conhecimento que não é duradouro (BAUMAN, 1998). Isto implica na flexibilidade para aprender o novo, a inovar, a criar articulações com a realidade e outras áreas de conhecimento, utilizar estratégias que motivem seus alunos etc.

\section{Considerações Finais}

Inferimos com base nos depoimentos dessas professoras que as representações sociais que possuem acerca do trabalho do professor se organizam em torno de imagens que referendam características da identidade do professor como: a vocação, amor á profissão, o gostar de crianças e saber lidar com elas, saber ensinar, ensinar o aluno a ser cidadão e preparálo para um futuro melhor e para o mercado de trabalho e a ter muita garra. A formação permanente comparece 
nessas representações como forma de fornecer suporte, desenvolvimento e aprimoramento á esses traços específicos do trabalho do professor uma vez que ele é de grande valor para a sociedade.

O trabalho do professor da contemporaneidade, na fala desses professores, entrevistados ancora ainda em sentidos como: demanda de formação inicial na qual a prática se articule com a teoria, uma vez que, o curso que fazem é essencialmente teórico; em novas metodologias de ensino que despertem no aluno interesse pela aprendizagem e; na qualificação para trabalhar com situações presentes na sala de aula: alunos com necessidades especiais, alunos que só possuem pai, e outros que só têm mãe, as diferenças, o preconceito, a sexualidade, bullying, etc.

As imagens e os sentidos mencionados que compõem as tendências de representações sociais dessas professoras sobre o seu trabalho se articulam ao questionamento e as contradições existentes sobre o modo de existência do professor, assim como de seu trabalho.

Todos os entrevistados destacam aspectos a serem superados no trabalho do professor, mas não sabem por onde começar. Dentre eles podemos destacar os seguintes: a) a ajuda dos pais dos alunos na educação e no aprendizado de seu filho; b) a distribuição do tempo; c) a desvalorização e a falta de reconhecimentos; d) os baixos salários praticados para a profissão e; e) a falta de infraestrutura física e pedagógica na escola.

Por entre a desvalorização do trabalho do professor e as demandas que se constroem na sociedade contemporânea sobre ele, é uma tarefa de difícil compreensão a complexidade que se enlaça na constituição deste profissional e de seu trabalho.

Por fim, esses professores partilham sentidos sobre os desafios que a profissão e o trabalho do professor vivem nos dias atuais, decorrentes das demandas do contexto histórico social contemporâneo, no qual o processo ensino-aprendizagem, tanto do professor quanto do aluno, requerem transformações não somente pelas inovações tecnológicas, mas também, pelo acelerado número de informações e transformações nas relações e modos de vida.

Por esta lógica, constatamos que as recontextualizações e as resignificações necessárias ao processo de ensino e da aprendizagem do professor se dinamizam juntamente com o contexto sócio histórico, tanto da profissão quanto do trabalho que realizam.

Esse estudo não esgota as problemáticas sobre o trabalho docente. Novos estudos fazem-se necessários para melhor compreensão à luz da perspectiva crítica.

\section{Referências}

BARDIN, L. Análise de conteúdo. Lisboa: Edições 70, 1994.

BAUMAN, Zygmunt. O Mal Estar da Pós Modernidade. Rio de Janeiro: Jorge Zahar, 1998.

BAUMAN, Zygmunt. (2009). A Arte da Vida. Rio de Janeiro: Zahar Editor, 2009.

GATTI Bernadete. A. Textos selecionados de Bernadete Gatti. Belo Horizonte: Autêntica Editora, Coleção Perfís da Educação, 2011.

GATTI, Bernadete Angelina; BARRETTO, Elba Siqueira de Sá e ANDRÈ, Marli Eliza Dalmazo de Afonso (2011). Políticas docentes no Brasil: um estado da arte. Brasília: UNESCO. Disponível em: http://unesdoc.unesco.org/images/0021/002121/21218 3por.pdf

HARGREAVES, A. Os professores em tempos de mudança: o trabalho e a cultura dos professores na idade pós-moderna. Portugal: Mc Graw - Hill, 1999.

JODELET, D. Les représentations sociales. Paris: PUF, 1989.

MOSCOVICI, S. A Representação Social da Psicanálise. Rio de Janeiro: Zahar, 1978.

MOSCOVICI,S. Representações Sociais: investigações em Psicologia Social. Petrópolis: Vozes, 2003.

NASCIMENTO, Ivany. (1998). A importância dos pais na construção da identidade do adolescente. Dissertação. Programa de Pós Graduação em Psicologia da Educação, Pontifícia Universidade Católica de São Paulo, 1998. Disponível em: http://revistas.pucsp.br/ index.php/interespe/article/download/21533/15786.

NASCIMENTO, Ivany. As representações sociais no campo das polifonias entre afetividade e a educação. Revista FAEEBA, v. 18, p. 27-34, 2009. Disponível

em: http://www.uneb.br/revistadafaeeba/edicoesanteriores

DEMARTINI. Zélia B. F. (1991). Magistério primário no contexto da 1 a República. (Relatório de Pesquisa) São Paulo, 1991. Disponível em: http://23reuniao. anped.org.br/textos/0217t.PDF 